\title{
Skin Targeting Approaches in Cosmetics
}

\author{
Swarnlata Saraf*, Chanchal Deep Kaur, Anshita Gupta, Nikita Verma \\ University Institute of Pharmacy, Pt. Ravishankar Shukla University, Raipur, Chhattisgarh, INDIA.
}

\begin{abstract}
Objective: To emphasize and summarize the main component of skin and approaches to target them. Methods: Skin targeting approaches in cosmetics is a review of all the relevant papers known to the author was conducted. Results: The exhaustive review on the basis of the previously reported paper revealed that the skin is a complicated and intact structure having vast of targeting component such as Keratin, Elastin fibres, ECM, MMPs, collagen, Hyaluronic Acid etc and apart from that the receptor and signalling pathway mediated skin targeting is also a promising approach to deliver bioactive at specific site of skin by the help of Surface engineered nanocarriers. Receptors like Epidermal Growth Factor Receptor (EGFr), interleukin-1 receptor (IL-1r), Tumor Necrosis Factor Receptor (TNFr), Platelet-Derived Growth Factor Receptor (PDGFr) and PlateletActivating Factor Receptor (PAF-r) are the types of receptor present in skin cells. These receptors are targeted by nanocarriers which are surface engineered by conjugating them ligands which show the specific affinity towards receptor present in the skin cells.
\end{abstract}

Key words: Skin, Targeting, ECM, MMPs, Collagen, EGFr, IL-1r, TNFr, PDGFr, PAF-r, Nanocarriers.

\section{INTRODUCTION}

Skin the outer covering or coat of human body also known as the integument serves as a link or interface between the body and environment. The most superficial organs of skin are prone and sensitive for interactions with the outside surrounding world. These may be either physical exposure like the sensation, defense etc. and/or psychological including inter or intrapersonal, societal etc. Cosmetics are used by humans from time immemorial. The cosmetic preparations and formulations are not only for superficial effect on skin, but they possess therapeutic and pharmacological activity which helps to keep the skin and its deeper layers safe and effective throughout the life. The market throughout the world is changing and demand for products such as Cosmeceuticals/skin products (like wrinkle fighters, anti-acne/anti-ageing and similar products), is ever increasing. Nutriceuticals and Cosmeceuticals together with vitamin supplements helps to nourish the skin and represents a link between nutrition and pharmaceuticals in the case of Nutriceuticals and cosmetics and pharmaceuticals in the case of Cosmeceuticals. ${ }^{1,2}$

The topical administration of drugs encapsulated into micro/nanocarriers is an innovative interesting alternative for reducing side effects and for increasing the therapeutic benefits. The major challenge associated with this approach is to increase the rate of penetration into deeper layer of skin. In modern era, with the advancement in technology it is now to develop formulations using modified techniques to overcome the skin barriers successfully and to reach penetration into the deep layers of the skin epidermis. Moreover, the use of ligands for targeting and as penetration enhancers is the easiest and one of the simplest strategies, causing temporary and reversible disruption of the stratum corneum bilayers leading to increased penetration of drug., ${ }^{3,4}$

Recent research have developed nutracosmetics which are amalgamation of health
Submission Date: 21-06-2019; Revision Date: 14-07-2019; Accepted Date: 03-08-2019

DOI: 10.5530/ijper.53.4.119 Correspondence: Dr. Swarnlata Saraf, Professor and Dean, University Institute of Pharmacy, Pt. Ravishankar Shukla University, Raipur-492010, Chhattisgarh, INDIA.

Phone: +919425522945

E-mail: swarnlatasaraf@ gmail.com

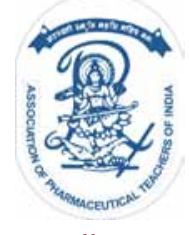

www.ijper.org 
and beauty aid products, which combine the benefits of nutrients and cosmetical ingredients with the elegance, skin feel and delivery systems of cosmetics. These products are using maximum natural ingredients along with the newer technologies like inclusion of novel drug delivery systems like liposomes, phytosomes, transferosomes, nanoemulsions, nanoparticles, microemulsions, nanocrystals etc. ${ }^{5-7}$

This chapter briefly discuss the structure of skin, its anatomy and physiology and explores the targeting approach into skin through topical delivery. This chapter also covers the ligands used for targeting; their methodology and carrier-based delivery systems used to overcome the primary barriers. The purpose of this chapter is to provide a basic knowledge about recent trends applicable for skin targeting, components used for targeting along with latest marketed products. The delivery systems for targeting through ligands are described as one of the potential strategies to overcome the skin barrier. NDDS like liposomes, niosomes, transferosomes, ethosomes and nanolipid carriers are discussed as potential carriers useful in cosmetics preparation. Each of these systems as delivery carriers and formulations are explored in the context of their application for promoting and skin targeting in cosmetics. ${ }^{8-10}$

\section{Skin Components and Physiology}

The Human Skin is divided into three regions: The epidermis, dermis and hypodermis as shown in Figure 1. Epidermis is again divided into four regions called stratum coreneum, stratum lucidum, stratum granulosum, stratum spinosum and stratum basale. Stratum Basel is the deepest layer of the epidermis consisting of keratinocytes, melaninocytes synthesizing melanin pigment and tactile cells which are also called as touch receptors. The area constituting dermis is the region of highly specialized cellular features namely collagen fibers, elastin fibers, fibroblasts and accessory structures. The most important area of our interest is the dermo-epidermal junction which comprises of hemidesmosome, basal lamina and subsequent connective tissue. The outermost layer of the epidermis, act as a key factor in maintaining the permeability barrier function. This dual role of skin membrane act as a limiting factor in the drug-molecule transport across the skin. ${ }^{11,12}$

The stratum corneum is the major barrier for the penetration of substances into the skin because of its heterogeneous composition and packed organization of corneocytes and the intracellular lipid matrix. The corneocytes are flat anucleated squamous cells packed primarily with keratin filaments and surrounded by a lipid matrix composed primarily of ceramides, choles- terol and free fatty acids. Two other cell types that are important in the context of skin tumor composition, melanocytes and Langerhans, are embedded between the basal keratinocytes. Melanocytes are dendritic cells capable of melanin production and Langerhans cells are antigen presenting cells that are responsible for the immune response in the skin. The top layer of skin is called the epidermis. ${ }^{13,14}$

It protects the underlying skin layers from the outside environment and contains cells that make keratin, a substance that waterproofs and strengthens the skin. The epidermis also has cells that contain melanin, the dark pigment that gives skin its color. Other cells in the epidermis allow us to feel the sensation of touch and provide the body with immunity against foreign invaders like germs and bacteria. The very bottom layer of the skin is the hypodermis. It contains the fat cells, or adipose tissue, that insulate the body and help it conserve heat. ${ }^{15-17}$

The layer between the epidermis and the hypodermis is the dermis. It contains the cells that give skin strength, support and flexibility. As a person ages, the cells in the dermis lose their strength and flexibility, causing the skin to lose its youthful appearance. Located in the dermis are sensory receptors. They allow the body to receive stimulation from the outside environment and experience pressure, pain and temperature. Small blood vessels provide the skin with nutrients and remove its waste products. Sebaceous glands produce the oil in the skin, which keeps it from drying out. ${ }^{18,19}$ The oil from the sebaceous glands also helps to soften hair and kill bacteria that get in the skin's pores. These oil glands are all over the body, except on the palms of the hands and the soles of the feet. The Figure 2 discussed below summarizes all the skin components which plays a crucial role in maintaining the vitality of the skin. ${ }^{20,21}$

The stratum corneum is a heterogeneous structure composed of protein enriched corneocytes embedded in a lipid matrix which contribute to the barrier function of stratum corneum. ${ }^{22}$

The extracellular matrix in the dermis is composed primarily of type I collagen, associated with type III collagen, elastin, proteoglycans and fibronectin. Three primary structural components of the dermis, collagen, elastin and GAGs have been the subjects of the majority of antiaging research and efforts for aesthetic-anti-aging strategies pertaining to the skin, from "anti-wrinkle creams" to various filling agents. ${ }^{23}$

Photoaging causes reduction in mature type I collagen and an increase in collagen III-tocollagen I ratio; massive 
accumulation of elastotic material in the upper and mid dermis also known as solar elastosis. ${ }^{24,25}$

Elastosis is due to accumulation of damaged elastin, the main component of elastic fibers and is associated with degeneration of the surrounding collagen meshwork. ${ }^{26}$

Collagen: Collagen is the main structural protein in the extracellular space in the various connective tissues in animals. As the main component of connective tissue, it is the most abundant protein in mammals, making up from $25 \%$ to $35 \%$ of the whole-body protein content. Collagen, in the form of elongated fibrils, is mostly found in fibrous tissues such as tendons, ligaments and skin. ${ }^{27}$ It is also abundant in corneas, cartilage, bones, blood vessels, the gut, intervertebral discs and the dentin in teeth. In muscle tissue, it serves as a major component of the endomysium. Collagen constitutes one to two percent of muscle tissue and accounts for $6 \%$ of the weight of strong, tendinous muscles. The fibroblast is the most common cell that creates collagen. First, a three-dimensional stranded structure is assembled, with the amino acids glycine and proline as its principal components. ${ }^{28}$ This is not yet collagen but its precursor, procollagen. Procollagen is then modified by the addition of hydroxyl groups to the amino acids proline and lysine. This step is important for later glycosylation and the formation of the triple helix structure of collagen. The hydroxylase enzymes that perform these reactions require Vitamin $\mathrm{C}$ as a cofactor and a deficiency in this vitamin results in impaired collagen synthesis and the resulting disease scurvy These hydroxylation reactions are catalyzed by two different enzymes: prolyl-4-hydroxylase and lysyl-hydroxylase. ${ }^{29}$

\section{Extra Cellular Matrix}

Wrinkles and stretch marks are the result of a lack of skin firmness and elasticity linked to a dramatic alteration of the cells and of the main constituents of the dermis located in the space surrounding the cells. The latter contains macromolecules, polysaccharides, Glycosaminoglycans (GAGs), fibrous protein (collagens, elastin), salts and water which together are known as the extra cellular matrix, responsible for tissue cohesion. The main structure proteins are collagens and elastin. ${ }^{30}$ The extra cellular matrix components are synthesised and secreted by cells such as the fibroblasts and degraded by enzymes called Matrix Metallo Proteinases (MMPs). MMP activity is regulated by various factors including activators like plasminogen, plasmin, Tissue Plasminogen Activator (t-PA) and Urokinase Plasminogen Activator (u-PA), but also by inhibitors like Tissue Inhibitors of Metalloproteinase (TIMPs), anti-plasmin and Plasminogen Activator Inhibitors (PAI 1 and PAI 2).

Collagen: The use of collagen-based biomaterials in the field of tissue engineering applications has been intensively growing over the past decades. Multiple cross-linking methods were investigated and different combinations with other biopolymers were explored in order to improve tissue function. Collagen possesses a major advantage in being biodegradable, biocompatible, easily available and highly versatile. However, since collagen is a protein, it remains difficult to sterilize without alterations to its structure. ${ }^{31}$

\section{Distribution, biosynthesis and molecular structure of collagen:}

The presence of collagen in all connective tissue makes it one the most studied biomolecules of the extracellular matrix $(\mathrm{ECM})$. This fibrous protein species is the major component of skin and bone and represents approximately $25 \%$ of the total dry weight of mammals. ${ }^{32}$ To this day, 29 distinct collagen types have been characterized and all display a typical triple helix structure. Collagen types I, II, III, V and XI are known to form collagen fibers. Collagen molecules are comprised of three $\alpha$ chains that assemble together due to their molecular structure. Every $\alpha$ chain is composed of more than a thousand amino acids based on the sequence -Gly-X-Y-. The presence of glycine is essential at every third amino acid position in order to allow for a tight packaging of the three $\alpha$ chains in the tropocollagen molecule and the $\mathrm{X}$ and $\mathrm{Y}$ positions are mostly filled by proline and 4-hydroxyproline. ${ }^{33}$

There are approximately twenty-five different $\alpha$ chain conformations, each produced by their unique gene. The combination of these chains, in sets of three, assembles to form the twenty-nine different types of collagen currently known. Few types are used to produce collagen-based biomaterials. Type I collagen is currently the gold standard in the field of tissue-engineering. The fibroblast is responsible for the majority of the collagen production in connective tissue. Collagen pro- $\alpha$ chain is synthesized from a unique mRNA within the rough endoplasmic reticulum and is then transferred to the Golgi apparatus of the cell. During this transfer, some prolines and lysines residues are hydroxylated by the lysyl oxydase enzyme. Specific lysines are glycosylated and then pro- $\alpha$ chains self-assemble into procollagen prior to their encapsulation in excretory vesicles. Following their passage through the plasma membrane, the propeptides are cleaved outside the cell to allow for the auto-polymerisation by telopeptides. This step marks the initiation of tropocollagen self-assembly into 
10 to $300 \mathrm{~nm}$ sized fibril and the agglomeration of fibril into 0.5 to $3 \mu \mathrm{m}$ collagen fibers, see Figure 3. Fibrilforming collagens are the most commonly used in the production of collagen-based biomaterials. ${ }^{34}$

Elastin: Elastin is a highly elastic protein in connective tissue and allows many tissues in the body to resume their shape after stretching or contracting. Elastin helps skin to return to its original position when it is poked or pinched. Elastin is also an important load-bearing tissue in the bodies of vertebrates and used in places where mechanical energy is required to be stored.

Elastic fiber is composed mainly of an amorphous component, which is extensively cross-linked elastin and a fibrillar component, which are primarily the microfibrils such as fibrillin, both of which are made of simple amino acids such as glycine, valine, alanine and proline. The total elastin ranges from 58 to $75 \%$ of the weight of the dry defatted artery in normal canine arteries. Comparison between fresh and digested tissues shows that, at $35 \%$ strain, a minimum of $48 \%$ of the arterial load is carried by elastin and a minimum of $43 \%$ of the change in stiffness of arterial tissue is due to the change in elastin stiffness. Elastin is made by linking many soluble tropoelastin protein molecules, in a reaction catalyzed by lysyl oxidase, to make a massive insoluble, durable complex cross-linked by desmosine and isodesmosine in an in vivo Chichibabin pyridine synthesis reaction. The amino acid responsible for these cross-links is lysine. ${ }^{35}$ Constant degradation of elastin and collagen from skin causes appearance of fine lines and wrinkle and causes premature aging. Skin aging is caused due to several factors. Healthy and functioning skin barrier is important protector against dehydration, penetration of various microorganisms, allergens, irritants, reactive oxygen species and radiation. The skin barrier may be specifically adjusted to allow penetration. For this reason daily skin care may increase skin regeneration, elasticity, smoothness and thus temporarily change the skin condition. However, it is necessary to stop the degradation of the skin primary structural constituents, such as collagen, elastin, to prevent the formation of wrinkles. Although the technology required to suitably deliver these compounds into the skin has not yet been developed, some products do promote the natural synthesis of these substances except elastin enhancing. There are various factors like environmental pollution, ultraviolet radiations, lack of nutrition, stress etc which causes activation of certain enzymes which degrade the skin and causes exploitation of collagen elastin and fibrils. Some of the enzymes are shown in the diagram below.

\section{Circulating collagen fragments}

Collagen is the main structural protein of all tissues in the body and is present indifferent collagen types. ${ }^{36}$ Of these types, the interstitial collagens I and III are primarily deposited in fibrotic connective tissue. Serum III procollagen (PIIINP) is a precursor of collagen type III and is known to be increased in different diseases associated with fibrotic processes. Type III collagen amino propeptide levels were found upregulated in lesional skin and serum of SSc patients, showing a positive correlation with the extent of skin involvement. 62-64. Type XVII collagen (BP180, BPAG2) is a structural component of hemidesmosomes mediating adhesion of keratinocytes to the underlying basement membrane. ${ }^{37}$

\section{Non-collagenous ECM constituents}

Higushi et al. found a positive correlation between the increased chondroitin and dermatan sulphate glycosaminoglycan content in SSc skin and the severity of skin involvement. ${ }^{38}$

\section{Matrix metalloproteinase}

MMPs represent a family of proteases, which are not only responsible for the degradation of collagens and other ECM proteins but which are also involved in the release and activation of many growth factors and cytokines.

Decorin binds noncovalently to the surface of fibrillar collagen, primarily type I and retards the rate and degree of collagen fibrillogenesis in vitro. This specific interaction is mediated by the protein core, whereas the glycosaminoglycan chain of decorin extends laterally from adjacent collagen fibrils, thereby maintaining interfibrillar spacing. ${ }^{39}$ This lateral orientation has also been demonstrated in collagen fibrils reconstituted in vitro in the presence of decorin. Thus, coordinated expression of decorin and associated collagens may regulate an orderly matrix assembly. Decorin purportedly binds to collagen types II, III and VI, fibronectin, C1q and transforming growth factor b. Moreover, decorin has been implicated in the control of cell proliferation by inducing arrest of tumor cells in the $G 1$ phase of the cell cycle. ${ }^{40}$

\section{3 skin Targeting Through Topicals}

Skin is a dynamic organ known for its protective functions. With a wide range of associated debilitating and untreatable conditions it has been explored for topical delivery of therapeutics for sustainable effects. In spite of the obvious advantages of the organ delivery of various hydrophilic molecules to skin has met with limited success. This could be attributed to the unique lipid composition and compact organization of stratum 
corneum which impedes the entry of such molecules in skin limiting their potential clinical translations. Recent approaches involve use of minimal invasive methods for macromolecules delivery to skin. However, issues with efficiency, toxicity, robustness and high costs limit their universal use. Thus, one of the key challenges in skin biology is to develop non-invasive, non-toxic and efficient methods for delivery of biomolecules to and through the skin. ${ }^{41}$ Contemporary skin cancer prevention advice focuses on stopping cell damage from ultraviolet radiation by minimizing sun exposure and liberally applying sunscreens. Sun avoidance does not address existing damage to skin cells and can lead to deficiencies of Vitamin D that is vital for the immune system to fight diseases that include skin cancer. Typical sunscreens prevent Vitamin D synthesis, still allow cell damage and have hormonal properties that may promote cancer growth. Although sunscreens do protect against sunburn, they have not been proven to prevent melanoma or basal cell carcinoma in humans.

There are various skin diseases and disorders like Xeroderma pigmentosa, (AID) Solar keratosis, Psoriasis, Skin cancer, Eczema, photosensitization etc which have can be cured by targeting those components which are crucially involved in the pathogenesis and progress of these diseases. Mere topical applications of medicament could serve to be an ideal treatment. Topical preparartions could also contains targeted moieties. ${ }^{42}$ Moreover, there is a great need to understand that topical are a mode of administration of drug but not a delivery system. Targeted moieties can be formulated into the form of topical preparations like gel, hydrogl, cream, lotions etc. for application at the desired site. Similarly various drugs that are lipid soluble when applied in the form of topical do not penetrate with the desired rate and their retention time also remains improper.

Targeting Topicals is necessary from the point of view of their skin persisting time. Assessing the bioavailability of drug molecules at the site of action provides better insight into the efficiency of a dosage form. However, determining drug concentration in the skin layers following topical application of dermatological formulations is a great challenge. The protocols followed in oral formulations could not be applied for topical dosage forms. In addition, the presence of enzymes in skin causes variation of the structure of molecules and alters topical bioavailability. Hence, the in vivo activity of dermatological formulations depends on bioavailability of drug within the skin at the site of action. ${ }^{43}$ In this context, researchers in the last few decades have given much emphasis on the assessment of skin kinetics of topical formulation. Following application of a topical drug formulation to the skin surface, it is likely that few processes occurs in a sequence such as release of drug from the dosage form, permeation of the drug into the skin barrier and exhibits the therapeutic responses such as onset of action, duration and magnitude of action.

\section{Agents used as Skin antiaging approaches}

\section{Topical medical agents or topical agents}

- Antioxidants

- Cell regulators

\section{Systemic agents}

- Hormone replacement therapy: Levels of Growth Hormone (GH) and insulin- like growth factor-1 (IGF-1), melatonin (nocturnal), TSH, thyroid hormones (T3), dehydroepiandrosterone (DHEA) (sulphated form and its urinary 17-ketometabolites), estrogens and testosterone are progressively decreasing. DHEA substitution has been proven to lead to an improvement of body condition, sexual activity, bone density and well-being. ${ }^{44}$

- Antioxidant: There are various integral approachs which are extensively used for preventing premature aging symptoms like wrinkle formation or to reduce skin complications arised as a result of improper nutritional requirements and lifestyle. Some of the agents that are widely used to maintain the vitality of the skin are shown below. ${ }^{45}$

\section{Targeting Skin Components}

Skin could be targeted using various natural skin components like elastin, collagen, keratin and skin enzymes shown in Figure 4. Biomarkers which reflect skin involvement of scleroderma patients include growth factors, cytokines and proteases as well as their inhibitors. Can also be used as targets for designing appropriate drug delivery systems. ${ }^{46}$

Collagen: Collagen is produced in the fibroblasts of the human dermis and is essential for healthy, firm skin. Both the quality and quantity of collagen decrease in ageing skin, often due to the effect of external factors such as exposure to the sun, especially UVA radiation. Collagen plays a pivotal role in maintaining skin structure and accounts for as much as $70 \%$ of the weight of the skin. The formulation of new collagen fibers is therefore essential for healthy, firm skin. The result of this cross-linking is that the skin loses its elasticity. Collagen could serves as a novel targets to deliver the drug at particular site. Collagen bound drug could not only easily uptake able but the bound collagen will be utilized by the skin for restoring its action. Collagen is biodegradable, posses weak antigenicity or low immu- 
nogenicity and has superior biocompatibility compared with other natural polymers, due to which it is considered as one of the best biomaterials for use in medical practice. Additionally, collagen can be processed into a number of forms such as sheets, tubes, sponges, powders, fleeces, injectable solutions and dispersions, all of which have found use in medical practice. Use of collagen for administration of antibacterial, anticancer drugs has shown it as one of the efficient drug delivery system in the field ophthalmology, wound and burn dressing, tumor treatment, etc. Currently its potential in tissue engineering is also being explored vigorously. ${ }^{47}$

Kasoju et al. in 2010, discussed the various aspects by which collagen can be used as a carrier in drug delivery. In his article he clearly states that collagen films, collagen shields, Collagen Sponges and collagen binded liposomes, niosomes etc have shown good results in cases of skin inflammations, burns, skin allergies, skin cancer etc. By understanding the concepts of high binding affinity and specificity of collagen, it can serve as better carrier for intargetted delivery drug. Collagen-based biomaterials are expected to become a useful matrix substance for various biomedical applications in the future. ${ }^{48}$

Neverthless, some agents that stimulate collagen production can also be served as targets for enhancing collagen production in the skin. In the past, topical application of soluble animal collagen was used in an attempt to stimulate the formation of collagen in the skin. The agents acting on skin shown in Figure 5. Tiedtke et al. in 2007, tried in their research work to stimulate the production and synthesis of collagen by using nano-encapsulated, stabilized, Vitamin C-derivative* (magnesium-L-ascorbyl phosphate) in the form of a so-called "intracellular-booster", which is a serum containing a high concentration of clearly defined carriers or delivery capsules. The nano-capsules had an average particle size of $150-200 \mathrm{~nm}$, enabling them to reach the appropriate layers of the dermis, which allows them to interact in the process of collagen synthesis. As a strong reducing agent it acts on the redox systems for the hydroxylation of proline to hydroxyproline, a characteristic part of the collagen structure. Efficacy of an encapsulated vitamin $\mathrm{C}$ derivative as a collagen stimulator was accessed by MTT cell stimulation assay and collagen stimulation assay. The results show that the nano-encapsulation of Magnesium Ascorbyl Phosphate (MAP) boosts both new cell growth and the ability of MAP to stimulate collagen synthesis in fibroblasts. ${ }^{49}$

Elastin: Despite their poor specificity, small molecule drugs are considered more powerful and effective than other current chemotherapies. Elastin also comes in this category and have the property to be a idela carrier for skin targeting. In a study by Ryu et al. in 2014, the potential of elastin like polypeptide was explored and discussed for skin targeting. A promising method for targeting these anticancer drugs to tumors, Elastinlike Polypeptides (ELP), has recently emerged. They showed that when an anticancer drug that was conjugated to an ELP and was administered and focal hyperthermia applied, the thermoresponsive properties and enhanced permeability and retention effects of the ELP facilitate drug aggregation within tumor tissues. By incorporating a cell penetrating peptide onto this ELP-chemotherapeutic construct, even greater drug uptake into tumor cells was achieved. The authors are of the opinion that ELP drug delivery technology is complementary and synergistic to current drug delivery modalities and based on existing hyperthermia technology. By using this technology to achieve chemotherapeutic targeting, efficacy can be improved and side effects reduced in comparison with current regimens, providing treatment alternatives and/or augmenting current therapies for cancer treatment. ${ }^{50}$

Certain types of proteins and peptides are also used now a days to facilitate the entry of drug to the target sites. Certain cosmetic peptides like Copper Glycyl-L-Histidyl-L-Lysinetripeptide (GHK) which acts as a carrier peptide, $\mathrm{Syn}^{\circledR}$-coll (Palmitoyl Tripeptide-5) DecorinylTM (a tetrapeptide) which acts as signaling peptides and Argireline ${ }^{\circledR}$, Vialox ${ }^{\circledR}$ and Syn ${ }^{\circledR}$-ake which act as Neurotransmitter-inhibiting peptides are commonly used. Some permeation enhancers are also used now a days to facilitate the entries of these proteins and peptides inside skin.

Hyaluronic acid: Hyaluronic Acid (HA, also called hyaluronan) is a linear polysaccharide consisting of two regularly alternating monosaccharides (D-glucuronic acid and $\mathrm{N}$-acetylglucosamine). Hyaluronic acid is naturally present in human tissues (e.g. in skin, ligament, main artery, tendon, valve, or synovial fluid) where it serves as a connective tissue organiser and water holding substance. HA is found in both layers of the skin - in the dermis and the epidermis, where it has a protective, structure stabilizing and shock-absorbing function. The total amount of hyaluronan in human skin is estimated to be about a third of the total amount of HA in the entire human body. As we age, the content of hyaluronan in the skin decreases, which may contribute to loss of freshness, hydratation, moisture and elasticity in the skin and the development of wrinkles. This is resolved by adding commercially produced hyaluronic acid to cosmetic products. Its ability to penetrate the skin and unique moisturizing and viscoelastic properties make the skin softened and restore its elasticity thereby 
a significant anti-wrinkle effect is achieved. Hyaluronic acid can be formulated in various cosmetic products such as creams, lotions, serums, shampoos, conditioners, bath oils, foundations, lipsticks or lip balms. Cosmetic products containing HA may also protect the skin against UV irradiation due to the free radical scaveging properties of HA. ${ }^{51}$

Although the main role of hyaluronan in cosmetics is as a highly effective humectant (moisturizer), it is also an ideal biomaterial for medical and pharmaceutical applications because of its strong biocompatibility, non-imunogenicity and biodegradability. The physicochemical properties of HA depend on the size of its molecule. Hyaluronic acid may be used as a filler to remove wrinkles in cosmetic surgery. It can be injected into the dermis to reduce facial lines and wrinkles as well as scars for longer than when common cosmetic products are applied. There is also better tolerability compared with the use of collagen. ${ }^{52}$

In a study by Morganti et al. in 2014, a multifunctional carrier of chitin-hyaluronan nanoparticles was prepared to deliver anti-aging active ingredients through the skin. The author through there study describes the process to produce Chitin Nanofibril-Hyaluronan nanoparticles (CN-HA), showing their ability to easily load active ingredients, facilitatepenetration through the skin layers and increase their effectiveness and safety as an anti-aging agent. Size and characterization of CN-HA nanoparticles were determined by Scanning Electron Microscopy (SEM) and Zetasizer, while encapsulation efficiency and loading capacity of the entrapped ingredients were controlled by chromatographic and spectrophotometric methods. Safeness was evidenced on fibroblasts and keratinocytes culture viability by the MTT (Methylthiazol) assay; anti-aging activity was evaluated in vitro measuring antioxidant capacity, anticollagenase activity and metalloproteinase and proinflammatory release; efficacy was shown in vivo by a double-blind vehicle-controlled study for 60 days on 60 women affected by photo-aging. In addition, the $\mathrm{CN}-\mathrm{HA}$ nanoparticles have shown interesting possibility to be used as active ingredients, for designing and making advanced medication by the electrospinning technology, as well as to produce transparent films for food packaging, by the casting method and can be used also in their dry form as tissues or films without adding preservatives. These unusual $\mathrm{CN}-\mathrm{HA}$ nanoparticles obtained from the use of raw materials of waste origin may offer an unprecedented occasion for making innovative products, ameliorating the quality of life, reducing pollution and safeguarding the environment's integrity. ${ }^{53}$
In another study by Kong et al. in 2011, an alcohol-free oil/water hyaluronic acid nanoemulsion was developed to be applied as transdermal carrier for active lipophilic ingredient. In vitro hemolysis, skin penetration and histological examinations were carried out using -tocopherol as model ingredient to assess skin permeability and bioavailability. Without any chemical enhancers, nanoemuslion performed desirable skin permeable capacity, being able to penetrate across stratum corneum and diffuse deeper into dermis compared with the control group (ethanol solution) via follicular and intercellular pathway. Penetration mechanism was preliminarily studied and suggested to be closely concerned with transmembrane concentration gradient, carrier characteristics and penetration enhancers. No irritation has been found in dermis and skin surface indicated hyaluronic acid nanoemulsions could be successfully used as purcutaneous delivery carrier of active lipophilic ingredient and favorable for drug and cosmetic applications. ${ }^{54}$

\section{Receptors and Signalling Pathways}

One of the most prominent signs of skin ageing is wrinkle formation. Wrinkles appear on the skin due to loss of elasticity caused by rapid degradation of collagen. This deficiency is contributed by the influence of intrinsic and extrinsic factors on mitogenic response and signal transduction pathways. Receptors like Epidermal Growth Factor Receptor (EGFr), interleukin-1 receptor (IL-1r), Tumor Necrosis Factor Receptor (TNFr), Platelet-Derived Growth Factor Receptor (PDGFr) and Platelet-Activating Factor Receptor (PAF-r) on activation. In order to reduce, delay and restore the effects of skin ageing, it is highly important to completely understandnits biological process. ${ }^{55}$

\section{EGFr and associated proteins involved in the signaling pathway}

The epidermal growth factor receptor (EGFR; ErbB1; HER1 in humans) is the cell-surface receptor for members of the epidermal growth factor family (EGFfamily) of extracellular protein ligands. The epidermal growth factor receptor is a member of the ErbB family of receptors, a subfamily of four closely related receptor tyrosine kinases: EGFR (ErbB-1), HER2/c-neu (ErbB-2), Her 3 (ErbB-3) and Her 4 (ErbB-4). Mutations affecting EGFR expression or activity could result in cancer. Epidermal growth factor receptor (EGFR) exists on the cell surface and is activated by binding of its specific ligands, including epidermal growth factor and Transforming Growth Factor $\alpha$ (TGF $\alpha$ ) (note, a full list of the ligands able to activate EGFR and other members of the ErbB. ErbB2 has no known 
direct activating ligand and may be in an activated state constitutively or become active upon heterodimerization with other family members such as EGFR. Upon activation by its growth factor ligands, EGFR undergoes a transition from an inactive monomeric form to an active homodimer-although there is some evidence that preformed inactive dimers may also exist before ligand binding. [citation needed] In addition to forming homodimers after ligand binding, EGFR may pair with another member of the ErbB receptor family, such as ErbB2/Her2/neu, to create an activated heterodimer. There is also evidence to suggest that clusters of activated EGFRs form, although it remains unclear whether this clustering is important for activation itself or occurs subsequent to activation of individual dimers

According to the literature, UV-activated EGFr is at least partly responsible for the activation of extracellular signal-regulated kinases (Erk1/2) directly, which then activates c-juntion. ${ }^{56}$

\section{PDGFr and associated proteins involved in the signaling pathway}

The PDGFRA gene provides instructions for making a protein called Platelet-Derived Growth Factor Receptor Alpha (PDGFRA), which is part of a family of proteins called Receptor Tyrosine Kinases (RTKs). Receptor tyrosine kinases transmit signals from the cell surface into the cell through a process called signal transduction. The PDGFRA protein is found in the cell membrane of certain cell types where a specific protein, called plateletderived growth factor, attaches (binds) to it. This binding turns on (activates) the PDGFRA protein, which then activates other proteins inside the cell by adding a cluster of oxygen and phosphorus atoms (a phosphate group) at specific positions (a process called phosphorylation). This process leads to the activation of a series of proteins in multiple signaling pathways.

The signaling pathways stimulated by the PDGFRA protein control many important cellular processes such as cell growth and division (proliferation) and cell survival. PDGFRA protein signaling is important for the development of many types of cells throughout the body.

PDGFr also leads to the production of MMPs via activation of Erk 1/2 and c-jun on stress. In vascular smooth muscles cells, factors ranging from physical exertion to psychological stress activate intracellular signaling and stimulate the synthesis of alfa plateletderived Platelet-Derived growth factor receptor (PDGFrA) and transcription factor c-fos/c-jun. In fibroblast cells, beta Platelet-Derived Growth Factor Receptor (PDG$\mathrm{FrB}$ ) activates $\mathrm{c}$-jun via the Erk1/2 pathway. These are ligand-dependant activation of receptors. However, UV rays activate the PDGFrB pathways, leading to MMPs production, which is ligand-independent activation. ${ }^{57}$

\section{PAF-r and associated proteins involved in the signaling pathway}

The platelet-activating factor receptor is a G-protein coupled receptor which binds platelet-activating factor. The PAF receptor shows structural characteristics of the rhodopsin (MIM 180380) gene family and binds Platelet-Activating Factor (PAF). PAF is a phospholipid (1-0-alkyl-2-acetyl-sn-glycero-3-phosphorylcholine) that has been implicated as a mediator in diverse pathologic processes, such as allergy, asthma, septic shock, arterial thrombosis and inflammatory processes.

According to the literature, UV light irradiation and acute thermal damage activates PAF-r-mediatedactivation of Erk1/2. PAF-r, not directly but indirectly, brings about activation of Erk1/2. The transactivation of EGFr by PAF-r involves a matrix metalloproteinasedependent cleavage and secretion of heparin-binding EGF-like growth factor (Hb-Egf) that activates the EGFr and subsequently phosphorylates Erk. ${ }^{58}$

\section{TNFr and associated proteins involved in the signaling pathway}

TNF receptor associated factors also known as TRAFs are a family of proteins primarily involved in the regulation of inflammation, antiviral responses and apoptosis. Currently, seven TRAF proteins have been characterized in mammals: TRAF1, TRAF2, TRAF3, TRAF4, TRAF5, TRAF6 and TRAF7. Except for TRAF7, these proteins share a relatively conserved secondary structure, including a namesake $\mathrm{C}$-terminal TRAF domain that mediates interactions with other signaling components such as the transmembrane.

TNF receptors and CD40 TNFr also participates in the production of MMPs when activated by environmental stress, such as UV rays. Experiments have proved that TNF receptor-associated factor 2 (Traf2/Trap3) bifurcates the TNF-mediated NFkB and c-jun pathways. Traf2 is an adaptor protein of the tumor necrosis factor receptor superfamily member $1 \mathrm{~B}$ (TNFr2) but not the tumor necrosis factor receptor superfamily member $1 \mathrm{~A}$ (TNFr1). ${ }^{59}$

\section{IL-1r and associated proteins involved in the signaling pathway}

Interleukin-1 receptor accessory protein is a protein that in humans is encoded by the IL1RAP gene. Interleukin 1 induces synthesis of acute phase and proinflammatory proteins during infection, tissue damage, or stress, by forming a complex at the cell membrane with an interleukin 1 receptor and an accessory protein. 
This gene encodes an interleukin 1 receptor accessory protein. Alternative splicing of this gene results in two transcript variants encoding two different isoforms, one membrane-bound and one soluble.

According to research papers, the IL-1r-mediated signaling pathway is activated by environmental stress. On activation, it activates the toll-like receptor protein interleukin-1 receptor-associated kinase-2 (Irak2), which further activates the TNF receptor associated factor 6 (Traf6). Traf6 is a member of the tumor necrosis factor receptor-associated factor family of proteins. It does not interact with Tnf. Instead, it

is associated with IL-1 via Irak. After Traf6 activation, mitogen-activated protein kinase is activated, which further activates c-jun and ultimately activates MMPs, which leads to collagen degradation.

Out of all the pathways mentioned here for a common target, c-jun was the only protein involved in all the pathways. Therefore, it is proposed to be the most potent target for drug design. Targeting this protein will decrease the degradation of collagen in the skin by blocking all these five pathways. Moreover, its expression increases in photo aged and old skin, proving its involvement in collagen degradation and wrinkle formation. ${ }^{60}$

\section{Topical Delivery Systems}

The new technologies employed in drug discovery lead to find many new powerful substances. The development of new drugs alone is not sufficient to ensure progress in drug therapy. Poor water solubility and insufficient bioavailability of the new drug molecules are main and common problems. Therefore, there is an increasing need to develop a drug carrier system that overcomes these drawbacks. This carrier system should have no toxicity (acute and chronic), have a sufficient drug loading capacity and the possibility of drug targeting and controlled release characteristics. Figure 6 shows the parabola of different carrier system in skin.

It should also provide chemical and physical stability for the incorporated drug. The feasibility of production scaling up with reasonable overall costs should be available. Size reduction is one of the methods to increase the solubility and hence the bioavailability of poorly water-soluble actives, which belong to the classes II and IV in the Biopharmaceutical Classification System (BCS). Colloidal systems, particularly those in the nanosize range, have been increasingly investigated in the last years because they can fulfill the requirements mentioned above. ${ }^{61}$

\section{Liposomes}

Liposomes are small artificial vesicles of spherical shape that can be created from cholesterol and natural nontoxic phospholipids. Due to their size and hydrophobic and hydrophilic character (besides biocompatibility), liposomes are promising systems for drug delivery. Liposome properties differ considerably with lipid composition, surface charge, size and the method of preparation. Figure 7 Furthermore, the choice of bilayer components determines the 'rigidity' or 'fluidity' and the charge of the bilayer. For instance, unsaturated phosphatidylcholine species from natural sources (egg or soybean phosphatidylcholine) give much more permeable and less stable bilayers, whereas the saturated phospholipids with long acyl chains (for example, dipalmitoylphos phatidylcholine) form a rigid, rather impermeable bilayer structure.

It has been displayed that phospholipids impulsively form closed structures when they are hydrated in aqueous solutions. Such vesicles which have one or more phospholipid bilayer membranes can transport aqueous or lipid drugs, depending on the nature of those drugs. Because lipids are amphipathic (both hydrophobic and hydrophilic) in aqueous media, their thermodynamic phase properties and self assembling characteristics influence entropically focused confiscation of their hydrophobic sections into spherical bilayers. Those layers are referred to as lamellae. ${ }^{62}$

Generally, liposomes are definite as spherical vesicles with particle sizes ranging from $30 \mathrm{~nm}$ to several micrometers. They consist of one or more lipid bilayers surrounding aqueous units, where the polar head groups are oriented in the pathway of the interior and exterior aqueous phases. On the other hand, self-aggregation of polar lipids is not limited to conventional bilayer structures which rely on molecular shape, temperature and environmental and preparation conditions but may selfassemble into various types of colloidal particles.

Liposomes are extensively used as carriers for numerous molecules in cosmetic and pharmaceutical industries. Additionally, food and farming industries have extensively studied the use of liposome encapsulation to grow delivery systems that can entrap unstable compounds (for example, antimicrobials, antioxidants, flavors and bioactive elements) and shield their functionality. Liposomes can trap both hydrophobic and hydrophilic compounds, avoid decomposition of the entrapped combinations and release the entrapped at designated targets. Because of their biocompatibility, biodegradability, low toxicity and aptitude to trap both hydrophilic and lipophilic drugs and simplify site-specific drug delivery to tumor tissues, liposomes have increased rate both as an investigational system and commercially as a drug- 


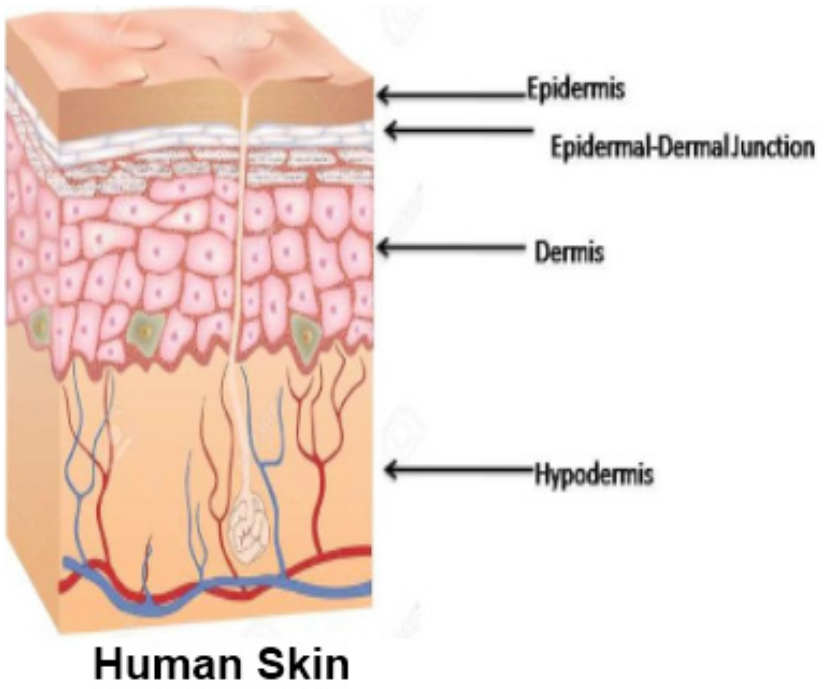

Figure 1: Different component of Skin.

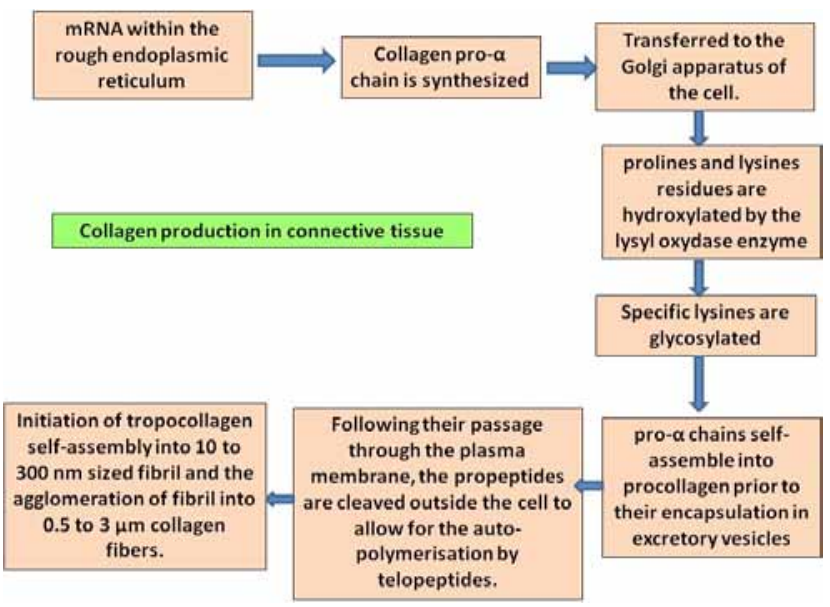

Figure 3: A schematic representation of the steps involved in collagen sysnthesis.

Enzymes effecting skin

\begin{tabular}{|c|}
\hline Protease, cellulase, \\
papain and chitinase: \\
Break down cellulose and \\
chitin.
\end{tabular}

\begin{tabular}{|c|c|}
\hline $\begin{array}{c}\text { Proteolytic Enzymes } \\
\text { break down proteins so that } \\
\text { the skin can better absorb their } \\
\text { components and so promote }\end{array}$ & $\begin{array}{c}\text { Digestive Enzymes: } \\
\text { stimulates digestion } \\
\text { like papain, } \\
\text { bromelain }\end{array}$ \\
\hline
\end{tabular}

Chemical Exfoliants:
dissolve and remove dead
cells from the surface of the
skin, leaving it smooth, fresh
and bright.

cell growth and renewal.

\begin{tabular}{|c|c|}
\hline $\begin{array}{c}\text { SOD, superoxide } \\
\text { dismutase: } \\
\text { Used in anti-ageing } \\
\text { formulas for its } \\
\text { protective action } \\
\text { against oxidative stress. }\end{array}$ & $\begin{array}{c}\text { DGAT-1, diacylglycerol } \\
\text { acyltransferase: } \\
\text { Enhancesthe action of } \\
\text { retinoicacid, which } \\
\text { accelerates epidermis and } \\
\text { hair renewal. }\end{array}$ \\
\hline
\end{tabular}

\begin{tabular}{|c|c|}
\hline $\begin{array}{c}\text { Lysyland prolyl hydroxylases: } \\
\text { Synthesizes the collagen } \\
\text { necessary to maintain the } \\
\begin{array}{c}\text { structure of the skin (they need } \\
\text { vitamin (to function). }\end{array}\end{array} \quad \begin{array}{c}\text { Metalloproteases: } \\
\text { are potentially toxic to the skin. } \\
\text { Excessive exposure to sunlight } \\
\text { causes them to multiply and to } \\
\text { destroycollagen and elastin. }\end{array}$ \\
\hline
\end{tabular}

Figure 4: Schematic representation of enzymes acting on skin.

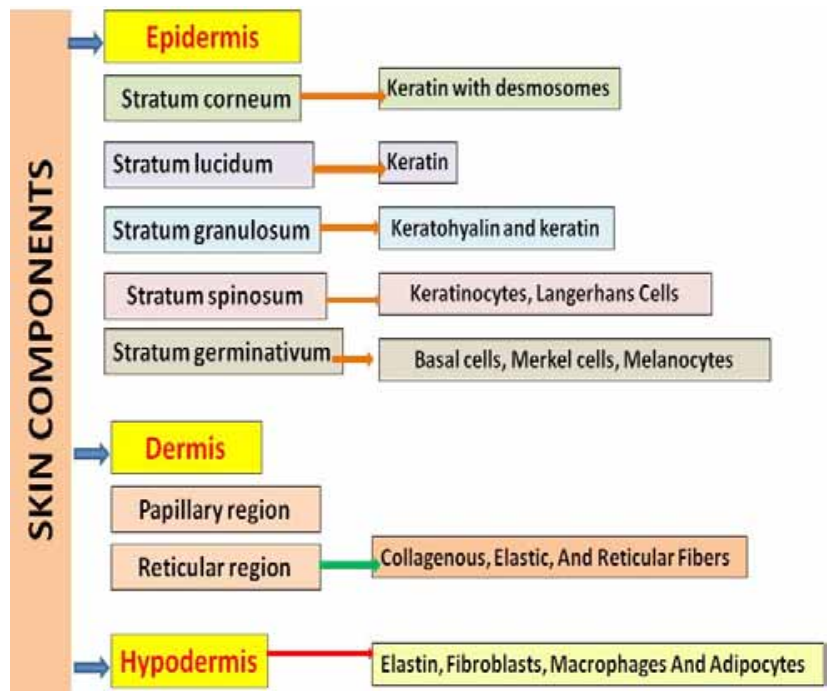

Figure 2: Showing the different skin components.

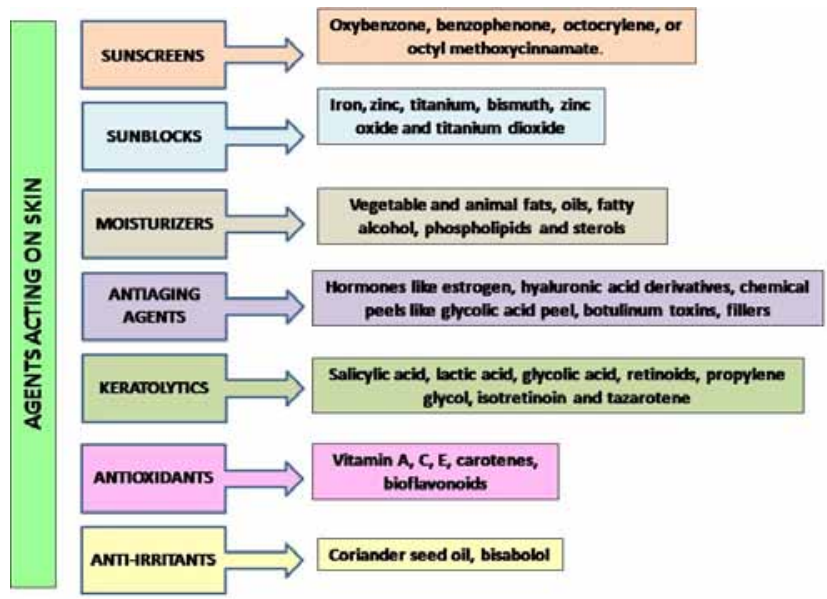

Figure 5: Showing Agents Acting on Skin.

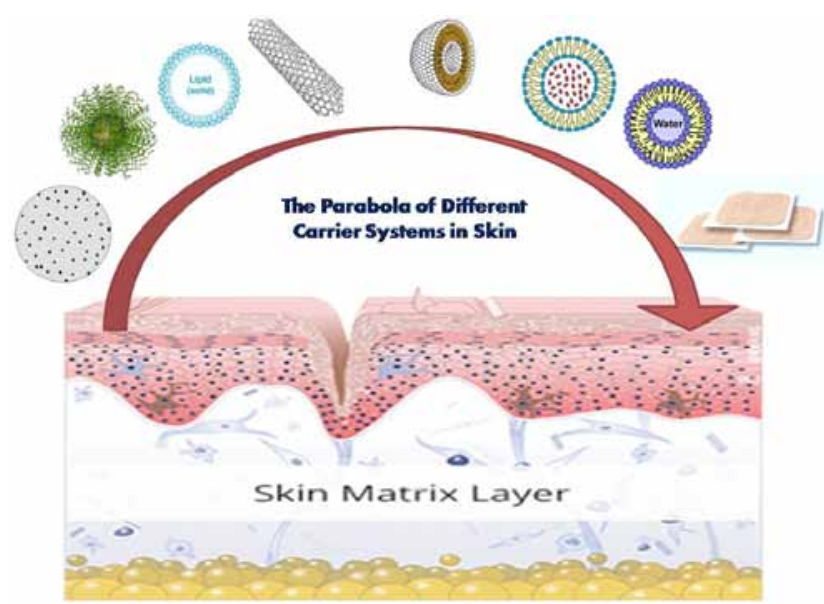

Figure 6: Showing The parabola of different Carrier systems in skin. 
delivery system Figure 8. Many studies have been conducted on liposomes with the goal of decreasing drug toxicity and/ or targeting specific cells.

\section{Niosomes}

Rigorous conditions required for handling liposomes under cryogenic atmosphere have prompted the use of non-ionic surfactant in vesicular drug delivery system, in place of phospholipids. Thus, the new vesicular delivery system consisting of unilamellar or multilamellar vesicles called niosomes, was introduced. Niosomes or non-ionic surfactant vesicles are microscopic lamellar structures formed on admixture of non-ionic surfactant of the alkyl or dialkyl polyglycerol ether class and cholesterol with subsequent hydration in aqueous media. Figure 9 shows the Niosomes method of preparation Niosomes can be changed or modified by the incorporation of other excipients like cholesterol, into the membrane and they can possess one or more lipid bilayers encapsulating an aqueous core. The bilayered vesicular structure is an assembly of hydrophobic tails of surfactant monomer, shielded away from the aqueous space located in the center and hydrophilic head group, in contact with the same.

Niosome possess an infra structure consisting of hydrophobic and hydrophilic mostly together and so also accommodate the drug molecules with a wide range of solubility. Addition of cholesterol results in an ordered liquid phase formation which gives the rigidity to the bilayer and results in less leaky niosomes. Dicetyl phosphate is known to increase the size of vesicles, provide charge to the vesicles and thus shows increase entrapment efficiency.

Other charge-inducers are stearylamine and diacylglycerol that also help in electrostatic stabilization of the vesicles. Niosomes have unique advantages over liposomes. Niosomes are quite stable structures, even in the emulsified form. Inclusion of cholesterol in niosomes increases its hydrodynamic diameter and entrapment efficiency. They require no special conditions such as low temperature or inert atmosphere for protection or storage and are chemically stable. ${ }^{63}$

Relatively low cost of materials makes it suitable for industrial manufacture. A diverse range of materials have been used to form niosomes such as sucrose ester surfactants and polyoxyethylene alkyl ether surfactants. Niosomes can entrap solutes in a manner analogous to liposomes. Niosomes are osmotically active and stable on their own, as well as increase the stability of the entrapped drugs.

Niosomes exhibits flexibility in their structural characteristics (composition, fluidity and size) and can be designed according to the desired situation. Niosomes can improve the performance of the drug molecules by delayed clearance from the circulation, better availability to the particular site, just by protecting the drug from biological environment and by controlled delivery of drug at a particular site. ${ }^{64}$

\section{Niosomes Interactions with the Cells}

Niosomes can interact with cells in many ways to cause niosome components associated with those cells. Five mechanisms are known for the niosome cell interactions as discussed below.

\section{Intermembrane transfer}

Intermembrane transfer to lipid components can take place upon close approach of two phospholipid bilayers without disruption of the niosomes of prejudicial of the membrane integrity. Interactions can take place between niosomes and lipoproteins and in certain circumstances, proceed to the extent of destroying the niosomes altogether. ${ }^{65}$

\section{Contact release}

Contact release of aqueous contents of niosomes occurs where contact with the cells causes an increase in permeability of the niosome membrane. This leads to release of water soluble solutes in high concentration in the close vicinity of the cell membrane through which these solutes may pass under certain circumstances. This phenomenon can provide very effective means for introducing materials into specific cells without ingestion of the whole niosome. ${ }^{66}$

\section{Adsorption}

Adsorption of niosomes to the cells surface occurs with little or no internalization of either aqueous or lipid components. It may take place either as a result of physical attractive forces or as a result of binding by specific receptors to ligands on the vesicle membrane.

\section{Fusion}

Close approach of niosomes and cell membrane can lead to fusion of the two resulting in complete mixing of niosomal contents into the cytoplasm. Endocytosis: The niosome is engulfed by the cell. The lysozyme present in the cytoplasm degrades or digests the membrane structure of niosomes.

\section{Transferosome}

Transfer some are special lipid aggregates that can penetrate efficiently even through the pores or constrictions that would be confining for other particulates of comparable size. This capability is due to the self-adaptable 
and extremely high deformability of the transfer some membrane.

Transfer some are artificial vesicles, being several orders of magnitude more deformable than standard liposomes. The deformability of liposomes for improved skin permeation of drug molecules can be achieved by using surfactant in appropriate ratio. Transfer some have the ability to overcome the skin permeation difficulty by squeezing themselves along the intercellular sealing lipid of the stratum corneum. The resulting flexibility of the transfer some membranes minimize the risk of complete vesicle rupture in the skin and allows transfer some to follow the natural water gradient, across the epidermis, after application on to the skin. Figure 10 shows the promising approach of transferosomes containing formulations in different dermal disorders Thus, targeted and controlled drug delivery can be achieved. In functional terms, it may be described as lipid droplet of such deformability that permits its easy penetration through the pores much smaller than the droplet size. It is highly stress-responsive, complex aggregate and adaptable. In the influence of the osmotic force gradient and hydration effect, the penetration of transfer some into the skin occurs. The transfer some are highly elastic in nature and can be deformed to gain access inside the sratum corneum approaching dermis and epidermis. Whenever the transfer some enters the tight cellular junction the lipioidal components deform themselves to penetrate inside the skin layer according to the pore size. While the components which are less flexible undergo dilution to come across the barrier reducing the rate of deformation enabling active passage of these vesicles cross the skin through pores. Here, the rate of deformation as well as penetration can be controlled by using a correct ratio of surfactant with the penetration enhancers. ${ }^{67}$

\section{Ethosomes}

Ethosomes were developed by Touitou et al. 1997, as additional novel lipid carriers composed of ethanol, phospholipids and water. They are reported to improve the skin delivery of various drugs. Ethanol is an efficient permeation enhancer that is believed to act by affecting the intercellular region of the stratum corneum. Ethosomes are soft malleable vesicles composed mainly of phospholipids, ethanol (relatively high concentration) and water. These soft vesicles represent novel vesicles carriers for enhanced delivery through the skin.

Ethosomes are non-invasive delivery carriers that enable drugs to reach the deep skin layers and / or the systemic circulation. The high concentration of ethanol makes the ethosomes unique, as ethanol is known for its disturbance of skin lipid bilayer organization. Therefore, when integrated into a vesicles membrane; it gives the vesicle the ability to penetrate the stratum corneum. Also, because of their high ethanol concentration, the lipid membrane is packed less tightly than the conventional vesicles, although it has equivalent stability, allowing a more malleable structure and improves the drug distribution ability in the stratum corneum lipids.

Ethosomes were reported to be effective at delivering molecules to and through the skin to the systemic circulation. The ethosomal carrier was previously tested for dermal delivery of the antiviral drug acylovir. The authors in the study reported a two-armed, doubleblinded, randomized clinical trial and demonstrated the efficiency of the ethosomal 5\% acylovir system, compared to a 5\% acylovir cream (Zovirax, ZC) for the topical treatment of herpetic infection. ${ }^{68}$

Enhanced delivery of chemicals from the ethosomal carrier was observed in permeation experiments with fluorescent probes. The amphiphillic flourescent probe D-289 was used to study skin penetration from trihexphenyl $\mathrm{HCl}$ ethosomes into nude mouse skin, after the non-occulusive application (Dayan and Touitou 2000) results showed that classic liposomes did not facilitate probe penetration into this skin, rather, resulted in only a small reservoir in the upper layers of skin. Using hydroethanolic solutions, a relatively deep penetration, but of relatively very low fluorescent activity was observed. The use of the ethosomal system resulted in increase in both depth and fluorescent activity. Ethosmes have also been reported to improve in vivo and in vitro skin delivery of many drugs both under occlusive and non-occlusive conditions. In comparison to other transdermal and dermal delivery systems,

Ethosomes enhance permeation of the drug through skin transdermal and dermal delivery.

Ethosomes are platforms for the delivery of large and diverse groups of drugs (peptides, protein molecules).

Ethosomal systems are much more efficient at delivering a fluorescent probe (quantum dots) to the skin in terms of quantity and depth.

Low risk profile-The technology has no large-scale drug development risk, as the toxicological profiles of the ethosome components are well-documented in the scientific literature.

High patient compliance-The ethosome drugs are administrated in a semisolid form (gel or cream), producing high patient compliance. In contrast, iontophoresis and phonophoresis are relatively complicated to use, which will affect patient compliance. 
High market attractiveness for products with proprietary technology. Relatively simple to manufacture with no complicated technical investments required for the production of ethosomes. ${ }^{66}$

The ethosomes system is passive, non-passive and available for immediate commercialization.

Various applications in the pharmaceutical, veterinary and cosmetic fields.

\section{Nanocarrier systems (SLN and NLC)}

Nanocarriers have demonstrated increased drug absorption, penetration, half-life, bioavailability, stability, etc. Nanocarriers are so small to be detected by immune system and they can deliver the drug in the target organ using lower drug doses in order to reduce side effects. Nanocarriers can be administrated into the organisms by all the routes; one of them is the dermal route.

Dermal exposure of smaller size (less than $10 \mathrm{~nm}$ ) of nanoparticles is more ruinous as it penetrates easily and shows long-lasting erythema, oedema and eschar formation, Hyperkeratosis and papillomatosis in irregular epidermis and fibrosis, hyperemia, erythema, intracellular edema and hyelinisation of collagen in dermis than larger ones (more than $30 \mathrm{~nm}$ ) which do not enter in the skin through transappendegeal route also. Following are the probable pathways of cellular uptake of nanoparticles -phagocytosis, macropinocytosis, clathrinmediated endocytosis, nonclathrin, non-caveolaemediated endocytosis, caveolae-mediated endocytosis or diffusion4, 71-74. Types of nanoparticles mostly used in cosmetics and dermal preparations are solid lipid nanoparticles, nanostructured lipid carriers, lipid drug conjugates. These are discussed below. ${ }^{69}$

\section{Solid Lipid Nanoparticles (SLN)}

At the beginning of the 1990's as an unconventional carrier system like Solid Lipid Nanoparticle (SLN) was developed over the existing conventional carriers, such as emulsions, liposomes and polymeric nanoparticles as a colloidal barrier for controlled drug delivery9, 21, 75-77. These particles are prepared from extremely purified triglycerides, complex glycerides mixtures or even waxes by replacing the liquid lipid (oil) of an o/w emulsion by $0.1 \%(\mathrm{w} / \mathrm{w})$ to $30 \%(\mathrm{w} / \mathrm{w})$ of solid lipid or a blend of solid lipid (i.e. lipids that are solid at room temperature and also at body temperature) and stabilized by surfactant(s) with a preferred concentration of $0.5 \%$ $(\mathrm{w} / \mathrm{w})$ to $5 \%(\mathrm{w} / \mathrm{w})$. The mean particle size of SLN is in submicron range, ranging from 40 to $1000 \mathrm{~nm} 75,78$. SLN have been developed and investigated by different analytical techniques like Photon Correlation Spectroscopy (PCS), Atomic Force Microscopy (AFM), Scanning
Electron Microscopy (SEM), for parenteral, pulmonary and dermal application routes.

\section{Nanostructured Lipid Carrier}

NLC which are second generation of SLN. Are composed of binary mixture of solid lipid and a spatially different liquid lipid as hybrid carrier and have an average size between 10-500 $\mathrm{nm}$. NLC consist of a mixture of specially blended solid lipid (long chain) with liquid lipid (short chain), preferably in a ratio of 70:30 to 99.9:01. Because of the oil presence in these mixtures, a melting point depression compared to the pure solid lipid is observed, but the blends obtained are also solid at room and body temperatures. The overall solid content of NLC could be increased up to 95\%. Many drugs have been successfully incorporated into SLN and NLC for different routes of administration. SLN and NLC revealed several advantages compared to the other colloidal carrier systems. They provide a controlled drug release and an increase in chemical stability of the incorporated drugs. Moreover, they are safe carriers which can be produced easily on large scale. ${ }^{70}$

Topical drug application has been introduced since long time to achieve several purposes on different levels (skin surface, epidermis, dermis and hypodermis). However, several problems have been reported with the conventional topical preparations e.g. low uptake due to the barrier function of the stratum corneum and absorption to the systemic circulation. A lot of research groups paid attention to the topical application of the SLN and NLC. Many features, which these carrier systems exhibit for dermal application of cosmetics and pharmaceutics, have been pointed out. SLN and NLC are composed of physiological and biodegradable lipids that show low toxicity. The small size ensures a close contact to the stratum corneum and can increase the amount of drug penetrated into the skin. Due to the occlusive properties of lipid nanoparticles, an increased skin hydration effect is observed. Furthermore, lipid nanoparticles are able to enhance the chemical stability of compounds sensitive to light, oxidation and hydrolysis

\section{Transdermal Drug Delivery Systems (TDDS Patches)}

TDDSs are among the most popular drug delivery systems. TDDSs are patches placed on specific areas of the body and enable certain drugs to penetrate through the skin layers, into the blood stream or the desired site of human organism. Compared to other dosage forms, this controlled delivery provides many advantages, such as: Improved patient convenience and compliance 


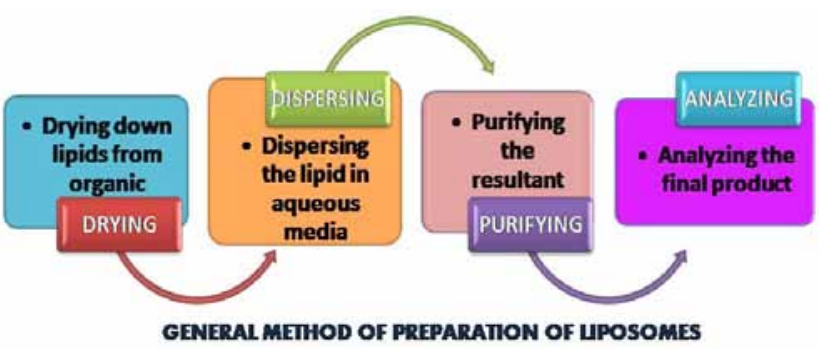

Figure 7: General Method of Preparation of Liposomes.

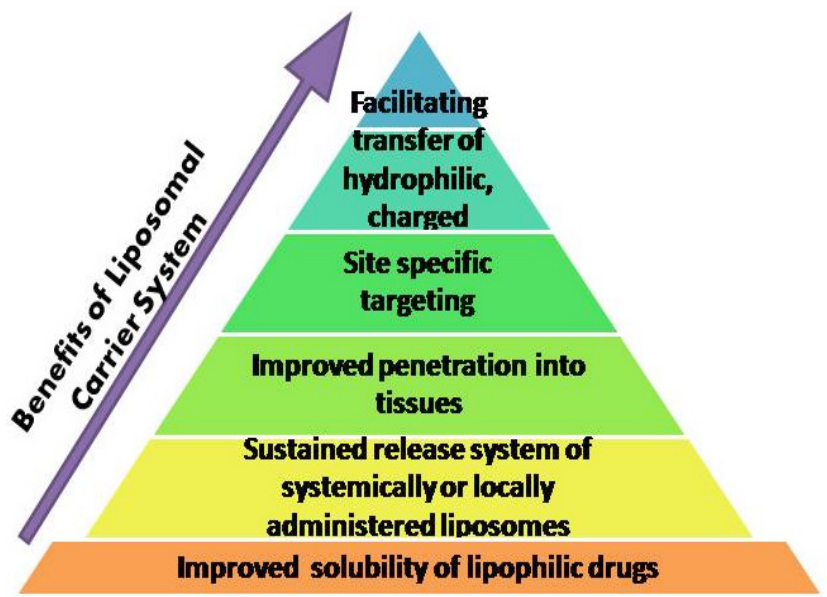

Figure 8: Showing Benefits of Liposomal Carrier system.

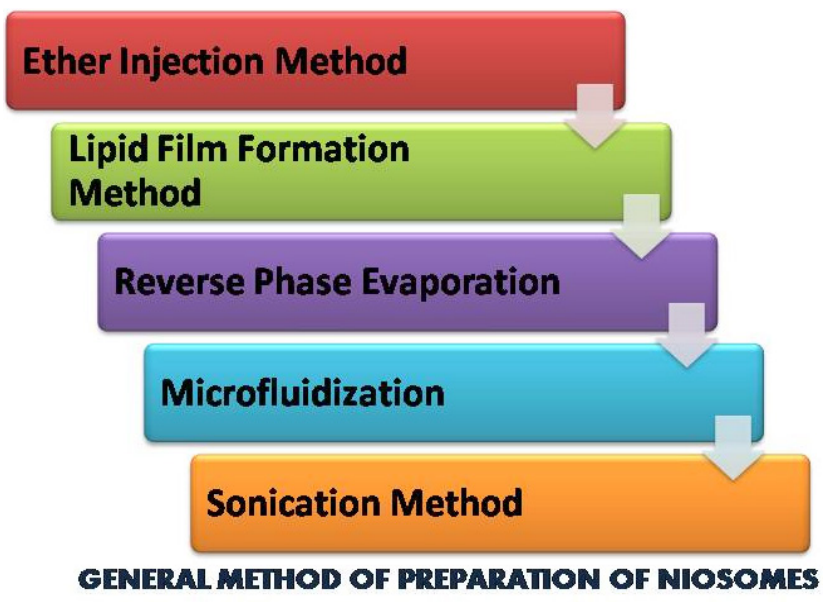

Figure 9: Showing Niosome s Method of Preparation.

Avoidance of hepatic metabolism, known as "first-passeffect" by the liver Improved safety. ${ }^{71}$

The therapeutic categories that benefit, today, by these Transdermal technologies relate to pain management, hypertension, angina pectoris, Parkinson disease, asthma, female or male hormone replacement therapy, contraception, nausea, incontinence etc.

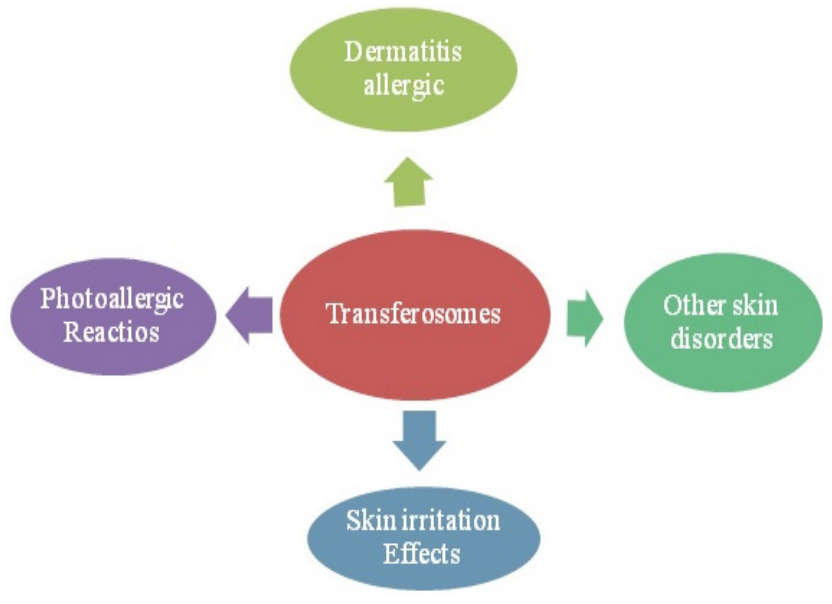

Figure 10: The promising approach of transferosomes containing formulations in different dermal disorders.

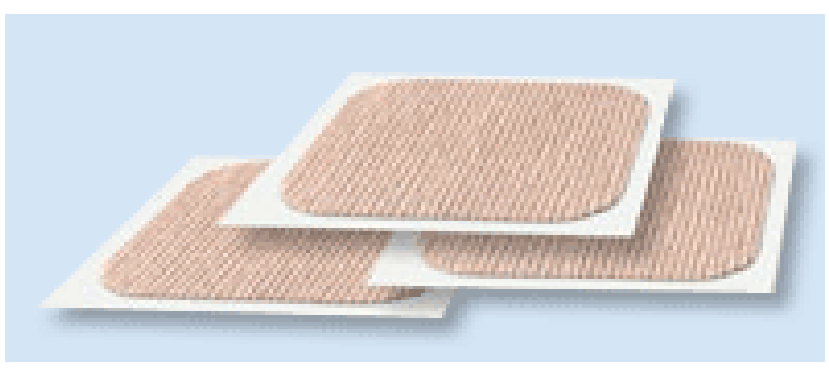

Figure 11: Showing Transdermal Patch

\section{Marketed Preparations}

The Table 1 and 2 shown below discuss various marketed preparations under various novel carrier category. Various marketed preparations have explored the market for anticaking and skin repair activities. There is a huge market of cosmetics which relay on novel carriers. For example liposomes, noisome etc. Marketed preparations of these delivery systems are efficient therapeutic cargoes also. There are some carrier based marketed preparations which are in clinical trial phase. The table shows the type of delivery system with their product name and activity profile. ${ }^{72}$

\section{Future Prospects}

In the last decades, targeting has become an established field in pharmaceutical research, cosmeceuticals and neutraceuticals. Targeted carrier-based drug delivery systems for skin targeting in cosmoceutical scan overcome the drawbacks associated with conventional available formulations by defeating the challenges of physiological barriers. Various colloidal/vesicular nano based particulate systems have been eveloped using latest technologies and few of them even achieved grand success in the market. Even today, there is an urgent 


\begin{tabular}{|c|c|c|}
\hline \multirow[t]{6}{*}{ S.No. } & $\begin{array}{c}\text { Type of } \\
\text { Photocarcinogenesis } \\
\text { And Other Mediated } \\
\text { Skin Disorders }\end{array}$ & $\begin{array}{l}\text { Altered Enzymes of } \\
\text { Significant Interest }\end{array}$ \\
\hline & $\begin{array}{l}\text { Solar Keratoses (SK) } \\
\text { and Bowen's Disease } \\
\text { (BD) }\end{array}$ & $\begin{array}{c}\text { Succinate Dehydrogenase } \\
\text { (Sdh), Glucose-6-Phosphate } \\
\text { Dehydrogenase (G6pdh) } \\
\text { And Lactate Dehydrogenase } \\
\text { (Ldh) }\end{array}$ \\
\hline & $\begin{array}{c}\text { Porphyric } \\
\text { Photodermatoses (PPD) }\end{array}$ & $\begin{array}{c}\text { Haem Metabolising } \\
\text { Enzymes }\end{array}$ \\
\hline & $\begin{array}{c}\text { Porphyria Cutanea } \\
\text { Tarda (Pct) }\end{array}$ & $\begin{array}{l}\text { Uroporphyrinogen } \\
\text { Decarboxylase }\end{array}$ \\
\hline & $\begin{array}{c}\text { Cockayne's Syndrome } \\
\text { (CS) }\end{array}$ & $\begin{array}{c}\text { Poly (ADP-Ribose) } \\
\text { Polymerase }\end{array}$ \\
\hline & $\begin{array}{c}\text { Xeroderma } \\
\text { Pigmentosumv (XP) }\end{array}$ & $\begin{array}{c}\text { DNA Polymerase, DNA } \\
\text { Ligase, a Dnase }\end{array}$ \\
\hline
\end{tabular}

need of designing site-specific/targeted cargoes or bioactive carriers for safe and effective delivery of drugs. NDDS is a tremendous and effective tool for by providing targeting after topical application with improved penetration and permeation across the skin. But the safety and stability profile are critical parameters to be focused at a comparatively cost-effective price with improved commercial applicability. The problem of tissue targeting is now by-passed through topical delivery. However, selective targeting through ligands and chemical enhancers for specific types of skin cells could be desirable for some applications.

In future, merging of micro carriers with nano carriers using high-throughput screening methodology can serve as innovative and beneficial concept for skin targeting using ligands. This technology will serve and provide a robust platform for investigating the effects of various physicochemical properties of nanocarrierson different layers of skin. This technology could exploit the advantages of micro and nanoaspects in a single delivery system. Even though skin acts as potential barrier for delivery of most of drugs; use of targeting approaches and topical delivery can create new horizon for effective and safe administration and treatment of various ailments. In order to develop effective nanoparticulate formulations, "Quality by Design" approach recommended by FDA is frequently applied to analyze and investigate the parameters and their influence on the prepared formulation.

\begin{tabular}{|c|c|c|c|}
\hline $\begin{array}{l}\text { Type of } \\
\text { Delivery } \\
\text { system }\end{array}$ & $\begin{array}{l}\text { Product } \\
\text { Name }\end{array}$ & Producer & Activity \\
\hline \multirow[t]{3}{*}{ SLN } & $\begin{array}{l}\text { Cutanova } \\
\text { Cream Nano } \\
\text { Repair Q10 }\end{array}$ & \multirow[t]{3}{*}{ Dr. Rimpler } & $\begin{array}{l}\text { Anti-aging and } \\
\text { skin repair }\end{array}$ \\
\hline & $\begin{array}{l}\text { Intensive } \\
\text { Serum } \\
\text { NanoRepair } \\
\text { Q10 }\end{array}$ & & skin repair \\
\hline & $\begin{array}{c}\text { Cutanova } \\
\text { Cream } \\
\text { NanoVital Q10 }\end{array}$ & & $\begin{array}{l}\text { Anti-aging and } \\
\text { skin repair }\end{array}$ \\
\hline \multirow[t]{4}{*}{ Ethosomes } & Nanominox & Sinere, Germay & $\begin{array}{l}\text { Anti-aging and } \\
\text { skin repair }\end{array}$ \\
\hline & $\begin{array}{l}\text { Supravir } \\
\text { Cream }\end{array}$ & Trima Israel & $\begin{array}{l}\text { Anti-aging and } \\
\text { skin repair }\end{array}$ \\
\hline & Cellulite EF & $\begin{array}{l}\text { Hampden } \\
\text { Health, USA }\end{array}$ & $\begin{array}{l}\text { To reduce } \\
\text { cellulite }\end{array}$ \\
\hline & $\begin{array}{l}\text { Decorin } \\
\text { Cream }\end{array}$ & $\begin{array}{c}\text { Genome } \\
\text { Cosmetics, U.S. }\end{array}$ & $\begin{array}{l}\text { Anti-aging and } \\
\text { skin repair }\end{array}$ \\
\hline Niosomes & Lancôme & Loreal, U.S & $\begin{array}{l}\text { Anti-aging and } \\
\text { skin repair }\end{array}$ \\
\hline \multirow[t]{6}{*}{ Liposomes } & $\begin{array}{c}\text { Doxil } \\
\text { (Doxorubicin) }\end{array}$ & SEQUUS, USA & $\begin{array}{l}\text { Kaposis } \\
\text { sarcoma }\end{array}$ \\
\hline & $\begin{array}{c}\text { Amphotec } \\
\text { (Amphotericin } \\
\text { B) }\end{array}$ & SEQUUS, USA & $\begin{array}{c}\text { Fungal } \\
\text { infections }\end{array}$ \\
\hline & $\begin{array}{c}\text { Fungizone } \\
\text { (Amphotericin } \\
\text { B) }\end{array}$ & Bristol squibb & $\begin{array}{l}\text { Fungal } \\
\text { infections }\end{array}$ \\
\hline & $\begin{array}{c}\text { Prostaglandin } \\
\quad-E 1\end{array}$ & $\begin{array}{l}\text { Netherland } \\
\text { Ventus }\end{array}$ & $\begin{array}{c}\text { Systemic } \\
\text { inflammatory }\end{array}$ \\
\hline & $\begin{array}{c}\text { Vitamin C with } \\
\text { Vitamin E and } \\
\text { Zinc }\end{array}$ & $\begin{array}{l}\text { Lipo CT M } \\
\text { Liposome -e } \\
\text { ncapsulated } \\
\text { Active }\end{array}$ & \\
\hline & Celadrin $^{\circledR}$ & $\begin{array}{l}\text { Pharmaceutical } \\
\text { Grade (USP) }\end{array}$ & $\begin{array}{l}\text { Topical } \\
\text { Liposome } \\
\text { Lotion }\end{array}$ \\
\hline $\begin{array}{l}\text { TDDS } \\
\text { Patch }\end{array}$ & $\begin{array}{l}\text { Nuvelle TS } \\
\text { Estradiol }\end{array}$ & Nuvelle TS & $\begin{array}{l}\text { Harmone } \\
\text { replacement } \\
\text { therapy }\end{array}$ \\
\hline
\end{tabular}

The basic need is to focus on the features and properties of formulation in order to extend its versatility with respect to its encapsulation efficiency, loading capacity, targeting ability to arrive and reach at an economical aspect for the topical delivery of drugs.

The only problem to overcome is from the front of regulatory approval. Regulatory agencies like U.S. FDA are still exploring different techniques to characterize 
drug's dermatopharmacokinetics. Parameters such as maximum quantity of drug active molecule in the SC $\left(\mathrm{C}_{\max }\right)$, time to reach maximum level $\left(\mathrm{T}_{\max }\right)$ and Area Under the Curve (AUC) are widely assessed in dermatokinetics studies. Different methods are reported for assessing pharmacokinetic profile of topically applied drug molecules which includes tape stripping, microdialysis, vasoconstrictor assay, confocal laser scanning etc. Certain dermatological product applied on the skin surface is likely to permeate into the deeper tissue layers and reach systemic circulation. Further, most of the molecules enters into the dermis are quickly cleared by the microvascular system, although few molecules retain in the skin and produce depot effect.

\section{ACKNOWLEDGEMENT}

Author would like to thanks Scholars of Cosmetic and Phyto- formulations Laboratory, University Institute of Pharmacy, Pt Ravishankar Shukla University, Raipur, Chhattiisgarh for their untiring efforts to make this manuscript.

\section{CONFLICT OF INTEREST}

The authors declare no conflict of interest.

\section{ABBREVIATIONS}

NDDS: Novel drug delivery system; GAGs: Glycosaminoglycans; ECM: Extracellular matrix; MMPs: Matrix Metalloproteinase; t-PA: Tissue Plasminogen Activator; u-PA: Urokinase PlasminogenActivator; TIMPs: Tissue Inhibitors of Metalloproteinase; PAI 1 and PAI 2: Anti-plasmin and Plasminogen Activator Inhibitors.

\section{REFERENCES}

1. Lademann J, Richter H, Teichmann A, Otberg N, Blume-Peytavi U, Luengo J, et al. Nanoparticles - An efficient carrier for drug delivery into the hair follicles. Eur J Pharm. 2007;66(2):159-64.

2. Alvarez-Figueroa MJ, Blanco-M' EJ. Transdermal delivery of methotrexate: iontophoretic delivery from hydrogels and passive delivery from microemulsions. Int J Pharm. 2001;215(12):57-65.

3. Alexander A, Dwivedi S, Giri TK, Saraf S, Saraf S, Tripathi DK. Approaches for breaking the barriers of drug permeation through transdermal drug delivery. Journal of Controlled Release. 2012;164(1):26-40.

4. Alvarez-Roman R, Barre G, Guy RH, Fessi H. Biodegradable polymer nanocapsules containing a sunscreen agent: preparation and photoprotection. Eur J Pharm Biopharm. 2001;52(2):191-5.

5. Alvarez-Roman R, Naik A, Kalia YN, Guy RH, Fessi H. Skin penetration and distribution of polymeric nanoparticles. J Controlled Release. 2004;99(1):5362.

6. Emerich DF, Thanos CG. The pinpoint promise of nanoparticle-based drug delivery and molecular diagnosis. Biomolecular Engineering. 2006;23(4):17184.

7. Lademann J, Richter H, Teichmann A, Otberg N, Blume-Peytavi U, Luengo J, et al. Nanoparticles--an efficient carrier for drug delivery into the hair follicles. Biopharm. 2007;66(2):159
8. Jangdey MS, Kaur CD, Saraf S. Efficacy of Concanavalin-A conjugated nanotransfersomal gel of apigenin for enhanced targeted delivery of UV induced skin malignant melanoma. Artificial cells, nanomedicine and biotechnology. 2019;47(1):904-16.

9. Anderson D. The acid-base balance of the skin. Br J Dermatol. 1951;63(89):283-96.

10. Bachhav YG, Patravale VB. Microemulsion based vaginal gel of fluconazole: Formulation, in vitro and in vivo evaluation. Int J Pharm. 2009:365(1-2):175-9.

11. Biruss $B$, Valenta $C$. The advantage of polymer addition to a non-ionic oil in water microemulsion for the dermal delivery of progesterone. Int $\mathrm{J}$ Pharm. 2008;349(1-2):269-73.

12. Khan J, Alexander A, Saraf S, Saraf S. Exploring the role of polymeric conjugates toward anti-cancer drug delivery: Current trends and future projections. International Journal of Pharmaceutics. 2018;548(1):500-14.

13. Chen H, Mou D, Du D, Chang X, Zhu D, Liu H, et al. Hydrogel-thickened microemulsion for topical administration of drug molecule at an extremely low concentration. Int J Pharm. 2007;341(1-2):78-84.

14. Chikakane $\mathrm{K}$, Takahashi $\mathrm{H}$. Measurement of skin $\mathrm{pH}$ and its significance in cutaneous diseases. Clin Dermatol. 1995;13(4):299-306.

15. Emerich DF, Thanos CG. The pinpoint promise ofnanoparticle-based drug delivery and molecular diagnosis. Biomol Eng. 2006;23(4):171-84.

16. Saraf S, Gupta A, Alexander A, Khan J, Jangde M, Saraf S. Advancements and avenues in nanophytomedicines for better pharmacological responses. Journal of Nanoscience and Nanotechnology. 2015;15(6):4070-9.

17. Bharali DJ, Khalil M, Gurbuz M, Simone TM, Mousa SA. Nanoparticles and cancer therapy: a concise review with emphasis on dendrimers. International Journal of Nanomedicine. 2009;4(1):1-7.

18. Djekic L, Primorac M. The influence of cosurfactants and oils on the formation of pharmaceutical microemulsions based on PEG-8 caprylic/capric glycerides. Int J Pharm. 2008;352(1-2):231-9.

19. Djordjevic L, Primorac M, Stupar M, Krasjinik D. Characterization of caprylocaproyl macrogolglycerides based microemulsion drug delivery vehicles for an amphiphilic drug. Int J Pharm. 2004;271(1-2):11-9.

20. Saraf S, GuptaA, Kaur CD, Jangde M, Saraf S. Dermatological Consequences of Photosensitization with an Approach to treat them Naturally. Pak J Biol Sci. 2014;17:167-72.

21. Draize J, Woodard G, Calvery $\mathrm{H}$. Methods for the study of irritation and toxicity of substances topically applied to skin and mucous membranes. J Pharmacol Exp Ther. 1944;82(3):377-90.

22. Eberlein-König B, Schafer T, Huss-Marp J, Darsow $U$, Mohrenschlager M, Herbert $\mathrm{O}$, et al. Skin surface $\mathrm{pH}$, stratum corneum hydration, trans-epidermal water loss and skin roughness related to atopic eczema and skin dryness in a population of primary school children. Acta Derm Venereol. 2000;80(3):18891.

23. Escribano E, Obach M, Arevalo MI, Domenech J, Queralt J. Rapid human skin permeation and topical anaesthetic activity of a new amethocaine microemulsion. Skin Pharmacol Physiol. 2005;18(6):294-300.

24. Jerant F, Johnson JT, Sheridan CD, Caffrey TJ. Early detection and treatment of skin cancer. American Family Physician. 2000;62(2):357-82.

25. Gunjan J, Swarnlata S. Topical delivery of Curcuma longa extract loaded nanosized ethosomes to combat facial wrinkles. Journal of Pharmaceutics and Drug Delivery Research. 2014;3:2-8.

26. Yuan F, Leunig M, Huang SK, Berk DA, Papahadjopoulos D, Jain RK. Microvascular permeability and interstitial penetration of sterically stabilized (stealth) liposomes in a human tumor xenograft. Cancer Research. 1994;54(13):3352-6.

27. Fluhr JW, Elias PM. Stratum corneum $\mathrm{pH}$ : Formation and function of the "acid mantle". Exogenous Dermatol. 2002;1(4):163-75.

28. Flynn GL. Comparision between in vivo techniques. Acta Pharm Suce. 1983;20:54-9.

29. Misaka H, Zachariasb N, Songc Z, et al. Skin cancer treatmentby albumin/5Fu loaded magneticnanocompositespheres in amouse model. Journal of Biotechnology. 2013;164(1):130-6.

30. Hengge UR, Ruzicka T, Schwartz RA, Cork MJ. Adverse effects of topical glucocorticosteroids. J Am Acad Dermatol. 2006;54(1):1-15.

31. Yano J, Hirabayashi K, Nakagawa S, et al. Antitumor activity of small interfering RNA/cationic liposome complex in mouse models of cancer. Clinical Cancer Research. 2004;10(22):7721-6. 
32. Jenning V, Gysler A, Schafer-Korting M, Gohla S. Vitamin A loaded solid lipid nanoparticles for topical use: Occlusive properties and drug targeting to the upper skin. Eur J Pharm Biopharm. 2000;49(3):211-8.

33. Soni S, Dixit VK. Comparison of passive and Iontophoretic Delivery of Timolo Maleate, pharmazie. Di Pharmazie. 1994;48(1):73-4

34. McGrath JA, Uitto J. Anatomy and Organization of Human Skin. In: Rook's Textbook of Dematology. Tony Burns, Stephen Breathnach. Neil Cox and Christopher Griffiths. 2010;1:3.1-53. Wiley-Blackwell, ISBN 978-1-40516169-5, Singapore.

35. Sanvicens N, Marco MP, Multifunctional nanoparticles--properties and prospects for their use in human medicine. Trends in Biotechnology. 2008;26(8):425-33.

36. Knorr F, Lademann J, Patzelt A, Sterry W, Blume-Peytavi U, Vogt A. Follicular transport route-Research progress and future perspectives. Eur J Pharm Biopharm. 2008;71(2):173-80.

37. Soni S, Jain SK, Jain NK. Effect of Penetration enhancers on Transdermal Delivery of Timolol Maleate. Drug Dev Indian Phar. 1992;18(10):1127-2235.

38. Jabr-Milane LS, Vlerken LEV, Yadav MS, Amiji M. Multi-functional nanocarriers to overcome tumor drug resistance. Cancer Treatment Reviews. 2008;34(7):592- 602.

39. Gupta A, Kaur CD, Jangdey M, Saraf S. Matrix metalloproteinase enzymes and their naturally derived inhibitors: novel targets in photocarcinoma therapy. Ageing research reviews. 2014;13:65-74.

40. Zhang L, Zhang N. How nanotechnology can enhance docetaxel therapy. International Journal of Nanomedicine. 2013;8(1):2927-41.

41. Muthu MS, Feng S. Theranostic liposomes for cancer diagnosis and treatment: Current development and pre-clinical success. Expert Opinion on Drug Delivery. 2013;10(2):151-5.

42. GuptaA, Saraf S, Kaur CD, Saraf S. The Potentials of Dehydroepiandrosterone (DHEA) in Skin ageing process. Research Journal of Topical and Cosmetic Sciences. 2013 Jul 1;4(2):43.

43. Slingerland $M$, Guchelaar $\mathrm{H}$, Gelderblom $\mathrm{H}$. Liposomaldrug formulations in cancer therapy: 15 years along the road. Drug Discovery Today. 2012;17(34):160-6.

44. Martinez JC, Otley CC. The management of melanoma and nonmelanoma skin cancer: a review for the primary care physician. Mayo Clinic Proceedings. 2001;76(12):1253-65. ISSN 0025-6196.

45. McCarron PA, Hall M. Incorporation of novel 1-alkylcarbonyloxymethyl prodrugs of 5-fluorouracil into poly (lactide-co-glycolide) nanoparticles. International Journal of Pharmaceutics. 2007;348(1-2):115-24. ISSN 03785173.

46. Verma N, Gupta A, Saraf S. Potential of Flavanoidal Rich Herbal Formulation in Treating Skin Aging Complications. Journal of Atoms and Molecules. 2015;5(2):880.

47. Merclin N, Bender J, Sparr E, Guy RH, Ehrsson H, Egstrom S. Transdermal delivery from a lipid sponge phase-iontophoretic and passive transport in vitro of 5-aminolevulinic acid and its methyl ester. Journal of Controlled Release. 2004;100(2):191-8. ISSN 0168-3659.

48. Merclin N, Bramer T, Edsman K. Iontophoretic delivery of 5-aminolevulinic acid and its methyl ester using a carbopol gel as vehicle. Journal of Controlled Release. 2004;98(1):57-65. ISSN 0168-3659.

49. Sanvicens N, Marco MP. Multifunctional nanoparticles-properties and prospects for their use in human medicine. Trends Biotechnol. 2008;26(8):425-33.

50. Mosallaei N, Jaafari MR, Hanafi-Bojd MY, Golmohammadzadeh S, Malaekeh-Nikouei B. Docetaxel-loaded solid lipid nanoparticles: Preparation, characterization, in vitro and in vivo evaluations. Journal of Pharmaceutical Sciences. 2013;102(6):1994-200.
51. Ohman EM, Rogers S, Meenan FO, McKenna TJ. Adrenal suppression following low-dose topical clobetasol propionate. J R Soc Med. 1987;80(7):422-4.

52. Poulsen BJ, Flynn GL. In vitro methods to study dermal delivery and percutaneous absorption. Percutaneous absorption: Mechanism, absorption and drug delivery. New York: Marcel Dekker. 1985;431-59.

53. Jain RK, Stylianopoulos T. Delivering nanomedicine tosolid tumors. Nature Reviews Clinical Oncology. 2010;7(11):653-64.

54. Alexander A, Dwivedi S, Giri TK, Saraf S, Saraf S, Tripathi DK. Approaches for breaking the barriers of drug permeation through transdermal drug delivery. Journal of Controlled Release. 2012;164(1):26-40.

55. Minelli R, Serpe L, Pettazzoni P, et al. Cholesteryl butyrate solid lipid nanoparticles inhibit the adhesion and migration of colon cancer cells. British Journal of Pharmacology. 2012;166(2):587-601.

56. Singh R, JrLillard JW. Nanoparticle-based targeted drug delivery. Experimental and Molecular Pathology. 2009;86(3):215-23.

57. Rizi K, Green RJ, Khutoryanskaya O, Donaldson M, Williams AC. Mechanisms of burst release from $\mathrm{pH}$-responsive polymeric microparticles. J Pharm. Pharmacol. 2010.

58. Soni S, Jain NK. Azones as Penetration enhancers. Indian Drugs: 1991;28(8):339-47.

59. Huang S. Liposomes in ultrasonic drug and gene delivery. Advanced Drug Delivery Reviews. 2008;60(10):1167-76.

60. Soenen SJH, Cocquyt J, Defour L, Saveyn P, DerMeeren PV, DeCuyper M. Design and development of magnetoliposome-based theranostics. Materials and Manufacturing Processes. 2008;23(6):611-4.

61. Schäcke H, Schottelius A, Döcke WD, Strehlke P, Jaroch S, Schmees N, et al. Dissociation of transactivation from transrepression by a selective glucocorticoid receptor agonist leads to separation of therapeutic effects from side effects. PNAS. 2004;101(1):227-32.

62. Kaur CD, Saraf S. Topical vesicular formulations of Curcuma longa extract on recuperating the ultraviolet radiation-damaged skin. Journal of Cosmetic Dermatology. 2011;10(4):260-5.

63. Kaur CD, Saraf S. Photoprotective herbal extract loaded nanovesicular creams inhibiting ultraviolet radiations induced photoaging. International Journal of Drug Delivery. 2011;3(4):699-711.

64. Schmid-Wendtner $\mathrm{MH}$, Korting $\mathrm{HC}$. The $\mathrm{pH}$ of the Skin Surface and Its Impact on the Barrier Function. Skin Pharmacol Physiol. 2006;19(6):296-302.

65. Saraf S.Dixit V.K. Influence of Electrical Factors on in vitro Iontophoretic Delivery of Timolol Meleate Drug Dev, Ind. Pharm, 1996: 22, 175-179

66. Sparavigna A, Setaro M, Gualandri V. Cutaneous $\mathrm{pH}$ in children affected by atopic dermatitis and in healthy children: A multicenter study. Skin Res Technol. 1999;5(4):221-7.

67. Allen TM, Cullis PR. Drug Delivery Systems: EnteringtheMainstream. Science. 2004;303(5665):1818-22.

68. Chandrakar S, Saraf S. Niosome-A Versatile Tool in Transdermal Drug Delivery. Research Journal of Pharmaceutical Dosage Forms and Technology. 2009;1(1):1-4.

69. Torchilin VP. Recent advances with liposomes as pharmaceutical carriers. Nature Reviews Drug Discovery. 2005:4(2):145-60.

70. Mehnert W, Mader K. Solid lipid nanoparticles: Production, characterization and applications. Advanced Drug Delivery Reviews. 2001;47(2-3):165-96.

71. Saraf S, Jeswani G, Kaur CD, Saraf S. Development of novel herbal cosmetic cream with Curcuma longa extract loaded transfersomes for anti-wrinkle effect. Afr J Pharm Pharmacol. 2011;5(8):1054-62.

72. Zhao Y, Brown MB, Jones SA. Pharmaceutical foams: Are they the answer to the dilemma of topical nanoparticles?. Nanomed Nanotechnol Biol Med. 2010;6(2):227-36. 


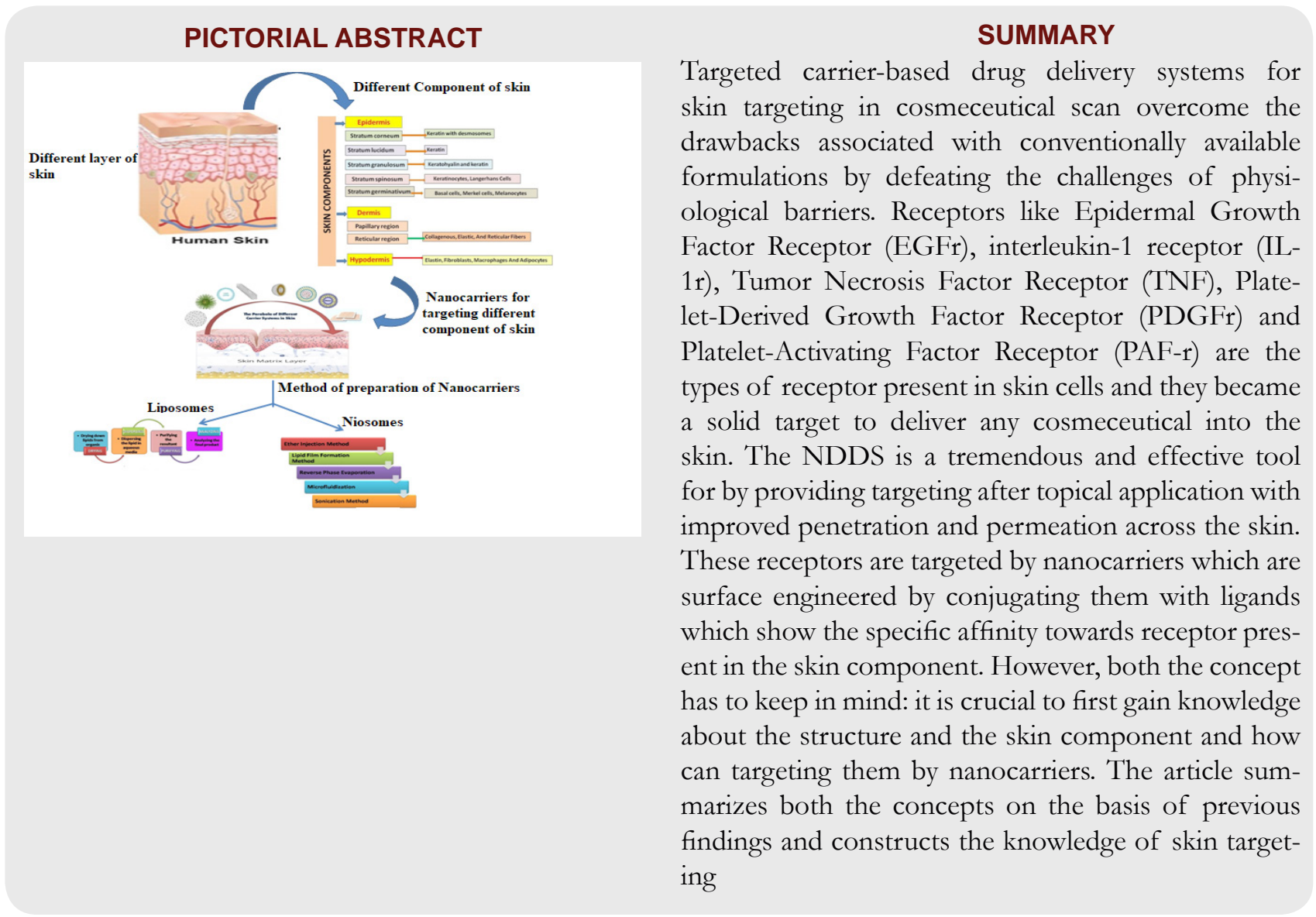

Cite this article: Saraf S, Kaur CD, Gupta A. Skin Targeting Approaches in Cosmetics. Indian J of Pharmaceutical Education and Research. 2019;53(4):577-94. 